Vol. 6, Issue 5, May 2019

\title{
The Criteria of the Environmental Interior Design
}

\author{
Mrs. Najlaa Yousif \\ Lecturer in the Department of Architecture and Interior Design, University of Bahrain, Esa town- Bahrain
}

\begin{abstract}
The current increasing interest in the importance of establishing the concept of environmental architecture in the design of modern buildings, adopting sustainability methods, formed a new challenge for interior designing, putting environmental considerations as top priorities in order to achieve the physical and spiritual needs of the user. Despite the modern tendency in the production of distinct architectural works in its designs, imitating the surrounding ecosystems, it lack in many of its interior design aspects embodying interior spaces that take into account not only the application of environmental determinants from a physical perspective that depends on the use of natural raw materials and attempts to maintain internal thermal performance, but they also lack the psychological comfort and organic communication between their internal spaces and environmental components, which depend on the ecological aspects and the application of modern technology. Hence, we find the importance of studying the criteria of the environmental Interior design.
\end{abstract}

Keywords: Environmental Interior Design, Sick Building Syndrome (SBS), Sustainability Goals, Embracing CoCreative Design Processes

\section{INTRODUCTION}

In the beginning, sustainable design was primarily directed at focusing on energies, resources and motivating people to avoid environmental damage. However, it failed to diagnose the characteristics affecting human health and well-being in the living and work environment, as well as its failure to diagnose the basic human needs of communication with nature, including the physical, emotional, intellectual and spiritual aspects. Sustainability proposals aiming at the weighting of economic values and paying attention to environmental health resulted in design patterns that have increased human alienation and isolation from beneficial communication with the natural environment. The negative impacts of these patterns have been incorporated into the concept of Sick Building Syndrome (SBS). Hence, sustainable design proposals have been focused on taking human dimensions into consideration after it was focused on energy and environmental conservation.

\section{DEFINITION OF ENVIRONMENTAL DESIGN}

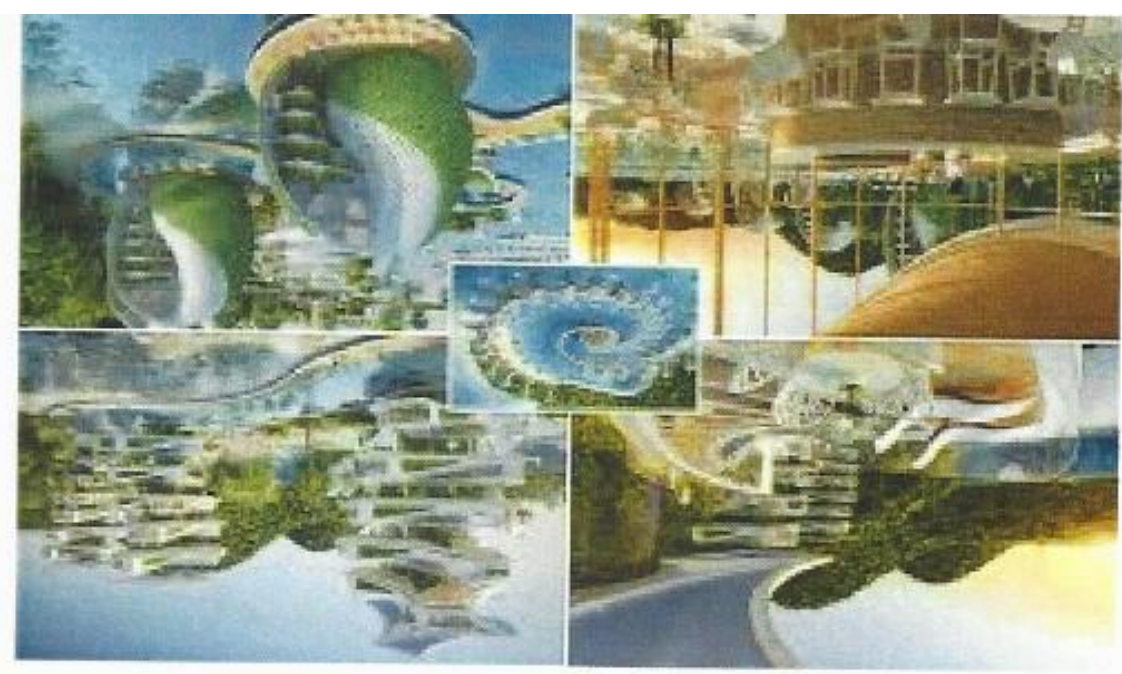

- A housing model that meets the requirements of comfort is established with monitoring the local climate as a strategy to minimise the use of mechanical machinery and to maximise the efficiency of positive exchange between the building and the environment.

- Modifying internal local climate conditions by examining the engineering characteristics and technology of the local building. The goal of environmental design is also to work towards a global policy to protect environmental 


\section{International Advanced Research Journal in Science, Engineering and Technology}

Vol. 6, Issue 5, May 2019

heritage, which is threatened by the effects of development and expansion that did not take into account local realities.

- A comprehensive study of all climate factors related to the identification and characters of the building site whether very hot or very cold weather - is the new approach called the environmental design.

- The concept of environmental design is profoundly linked to the awareness that technological progress can find a solution to reduce burdens on the environment and halt the depletion of natural resources.

- The main factors that negatively affect the environment stem mostly from the need to dispose of large quantities of non-renewable energy.

- In this regard, environmental design has a key role to play in renewing the efficiency of the energy of the built environment, as large quantities of polluting gas emissions come from air conditioning and heating systems.

- In developing countries, the law sets standards for energy saving by controlling maximum permitted consumption in buildings and encouraging the use of renewable resources (solar and wind).

- Reducing the environmental impact require first and foremost the reduction of energy consumption.

- Green Building is one of the models that can become a reference point for residences with low energy consumption.

\section{REASONS FOR THE EMERGENCE OF ENVIRONMENTAL DESIGN}

- Setting places inhabited by humans by respecting the essence of the building site.

- Improve the relationship between the building and the environment.

- Improve the quality of life and psychological and physical well-being.

- Maintain the ecosystem.

- Use of natural resources (water, plants, climate) and not causing harmful emissions (smoke, gas, water, and waste).

- Design of flexible buildings for removals, replacements, additions or extensions.

- $\quad$ Provide a wide range of renewable energy sources.

- Use environmental friendly materials and technologies as a priority.

\section{WHAT IS SUSTAINABILITY?}

Sustainability - in a broad sense - is the ability to maintain a particular process or situation and is now more widely used for biological and human systems.

In an ecological context, sustainability can be defined as the capacity of the ecosystem to maintain ecological processes, functions, biodiversity and productivity in the present and future.

In order for humans to live in a sustainable manner, the resources of the earth must be used at a rate that would enable them to be renewed. However, there is clear scientific evidence that humanity is living in an unsustainable manner and that there is a need for the human reuse of natural resources within sustainable limits.

Since the 1980s, the idea of sustainability rights has become increasingly linked to the integration of economic, social and environmental fields. In 1989, the World Commission on Environment and Development defined sustainability as "fulfilling" the needs of the present, without compromising the ability of future generations to meet their needs.

(14-41) Sustainability Goals:

- Equality and equity between generations and to provide future generations with the same environmental needs as present.

- Separate economic growth from environmental degradation, managing economic growth is based on resource rationalisation and reducing pollution.

- Integration and complementing. To achieve integration between the environmental, social and economic sectors when setting sustainability policies.

- Flexibility with the environment and to conserve it, and enhancement of adaptive capacity to the ecosystem.

- Preventing damage that is difficult to cancel, over the long term, to ecosystems and human health.

- Ensure fairness in distribution, avoid inequality or high environmental costs.

- Spread educational awareness and popular participation among people and communities to discuss problems and develop good solutions.

(24-4 )2) Sustainability Measurement:

It is a term that indicates quantitative measurements that are used mainly for sustainability management.

Measurements used for sustainability include environmental, social and economic sustainability, both individually and in different combinations (indicators, standards, audits, indices, accounting systems, etc.) and can be applied at all levels (global and local). 


\section{International Advanced Research Journal in Science, Engineering and Technology}

Vol. 6, Issue 5, May 2019

Sustainability measurement can be considered from an environmental perspective as a comparison or balancing the quantity of resources with demand in ecosystems. The greater the quantitative demand for environmental resources, especially non-renewable causing disruption to ecosystems, the less the sustainability. The relation between the use of non-renewable environmental resources and sustainability is inverse.

(34-43) Sustainable Development:

Sustainable development is "the development that meets the needs of the present from natural resources without diminishing the ability of future generations to obtain their natural resource needs".

The word development in this definition indicates two concepts:

1. The concept of needs: This consists of the conditions of maintaining an acceptable standard of living for all individuals. These include: (iI) basic needs such as food, clothing, housing and work; (ii) grant equal opportunities to all individuals to raise their standard of living.

2. The concept of limits: This is the capacity of the environment to meet the needs of the present and the future determined by technology and social organising authorities.

Limits consist of: natural limits such as limited resources, declining productivity resulting from over-exploitation of resources, low water quality and reduced biodiversity.

It would therefore be better to meet needs without increasing limits, which would lead to the very simple conclusion that all political, technical and social decisions could be assessed in the light of sustainable development through the two previous concepts.

- $\quad(1-3-4)$ The Relation between Sustainable Development and the Environment:

Sustainable development achieves a balance between the ecosystem and the economy, and it contributes to maximising growth as well. Development and the environment are two interrelated processes that cannot be separated because environmental protection from pollution is an essential element of sustainable development. This new model of development - sustainable development - is the most important development in modern development thought in recent decades. This is because the prevailing developmental models are concerned only with economic growth, which impacts other systems; especially the ecosystem. Sustainable development is distinguished because it makes conform between the environmental and natural component on one hand and the social and economic component on the other.

Thus, sustainable development can be defined as "the economic activity that leads to the promotion of social welfare with the utmost care for the available natural resources and with minimal damage and abuse of the environment".

\section{(4-4) Sustainable Urban Design}

The concept of sustainable urban design is one of the concepts found in various human civilisations since the dawn of history. However, it has become popular in recent decades due to the low interest of humans in preserving the environment due to un-nationalised use of technological progress. The concept stems from the attempt of urban designers to deal sensitively with the environment of the earth in order to maintain it healthy for human life in the present and future. Since the oil crisis of the 1970s, the global orientation began to rationalise the consumption of traditional energy resources and to develop the use of renewable energy resources.

\section{(14-4-41) Principles of Sustainable Urban Design}

Designers who care about the environment and preserve it in their designs use one of three approaches to deal with the natural environment in producing adequate urban designs for their users: The first approach is to use raw building materials from nature in the construction of urban areas such as clay, soil, wood, etc. The second approach is to utilise advanced technology in the establishment of urbanisation, taking into account the climatic conditions and providing the possibilities of recycling or reuse, and to utilise renewable energies positively. The third approach is to integrate the two mentioned approaches according to the nature of the site, where the project is built, and the nature of the project. Each of the three approaches adopts several principles aimed at establishing an eco-friendly urbanisation that uses the least amount of energy, preserves its natural resources and causes the least amount of pollution to the natural environment. The most important of these principles are:

- $\quad$ Understanding Place

Sustainable design begins by understanding the nature of the place and treating the environment with great care so that it can be liveable without destroying it. Understanding place also helps to take procedures and practices such as the efficiency of energy resources in cooling, heating, lighting and other uses by applying design solutions that achieve the human's thermal comfort in a natural way with the use of the least amount of energy. 


\section{International Advanced Research Journal in Science, Engineering and Technology}

Vol. 6, Issue 5, May 2019

- $\quad$ Connecting with Nature

The design can benefit from the natural environment surrounding the site and be inspired by it. Thus, the design ideas can be integrated with the surrounding environment because it is part of it.

- Understanding Natural Processes

There is no waste in nature; as the wastes of an organism is the food of another organism - as natural systems are made of closed loops - this makes the environment an integrated system . The attempt is to apply this to urban design to become a micro-system of the ecosystem.

- $\quad$ Understanding Environmental Impact

By assessing the site, energies, toxicity of materials, energy efficiency, building technology, materials and power. The negative impact on the environment can be mitigated by the use of sustainable materials in construction and finishing, the use of building materials that do not produce emissions that harm humans or the local environment, and the recycling of building materials more than once.

- $\quad$ Embracing Co-Creative Design Processes:

Sustainability designers believe in the importance of considering any view during the design process, whether from other professionals in the same career, or from local inhabitants or users.

\section{- $\quad$ Understanding People}

Sustainable design should take into consideration a wide range of cultures, ethnicities, religions and the habits of the people who use the built environment. This means the understanding of the social and economic environment to achieve the appropriate urbanisation of the local environment and to fulfill the users' needs.

\section{SUSTAINABLE INTERIOR DESIGN ALTERNATIVES - REUSE}

There are three concepts that reflect sustainable design thinking: Recycle, Reuse, and Reduce, which means reducing the consumption of natural raw materials and energy. In order to apply these concepts in the field of interior design and furniture, consideration must be given at the beginning stages of the design to using materials that are recyclable and environmentally safe. For example, particleboards, which are made of $100 \%$ recycled wood fibers, can be used in wall panels if wood surfaces are needed, so no new timber is cut off from trees. Another example is fibers manufactured of recycled green materials. These panels can be recycled again after they have been used.

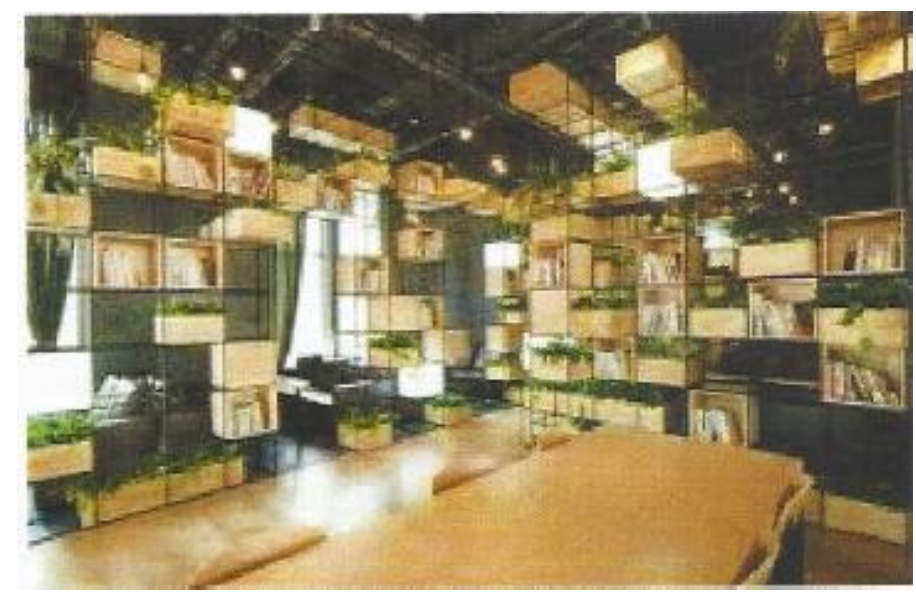

In the field of furniture manufacturing, the concept of sustainability can be realised through several themes, including the reuse of furniture in another usage after the completion of its basic function, the use of recycled materials and the implementation of designs in a manner that conserves energy and reduces the use of natural raw materials.

(15-51) Sustainable Interior Design:

The Economic Benefit of Achieving Sustainability in Interior Design: The use of recycled materials in the interior design reduces the actual cost of the final product. Since the furniture industry invests billions of dollars, reducing costs is vital for the industry. Moreover, LEED financially supports designs aimed at achieving the concept of sustainability. 


\section{International Advanced Research Journal in Science, Engineering and Technology}

Vol. 6, Issue 5, May 2019

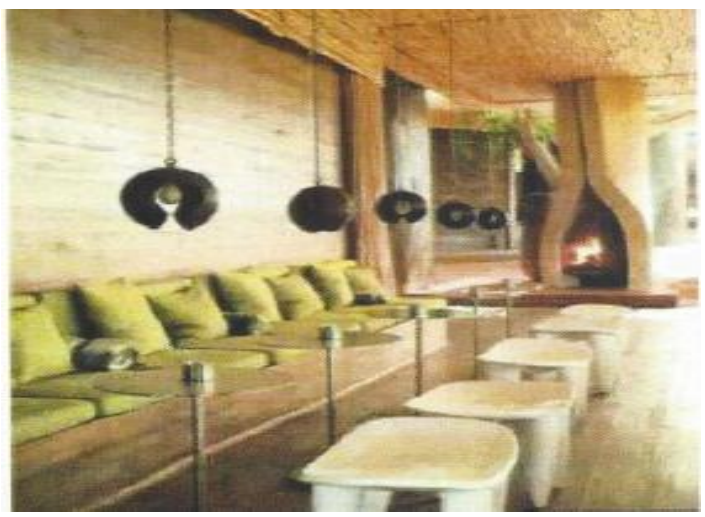

(25-52) Sustainable Furniture Design

Recycled Furniture: Recycling is no longer limited to the recycling of raw materials of a product so that we can re-use the same product with the same raw materials; for example, recycling paper to produce paper again. However, the concept developed to result in recycling the parts of the product to manufacture another different product. This is clearly demonstrated in the field of recycled furniture manufacturing. The following examples illustrate this:

2.1. Furniture made from tyres, which cannot be used anymore. (Fig. 64)
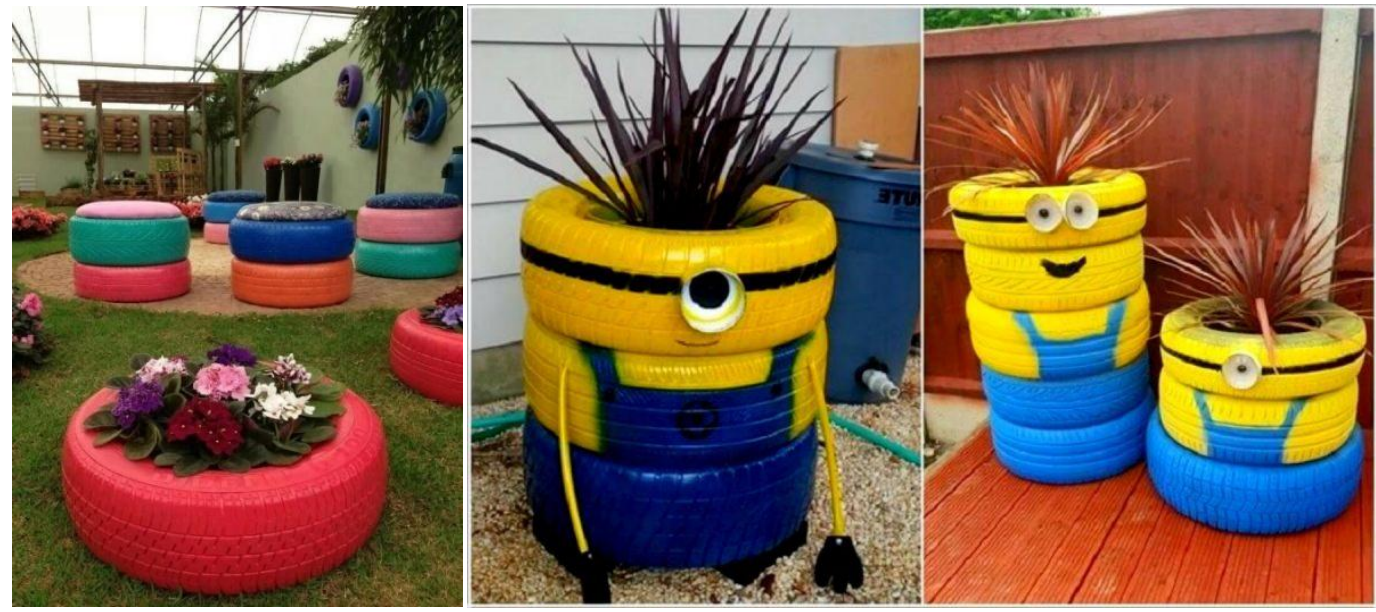

2. Furniture made from car spare part and repaint. (Fig. 5)
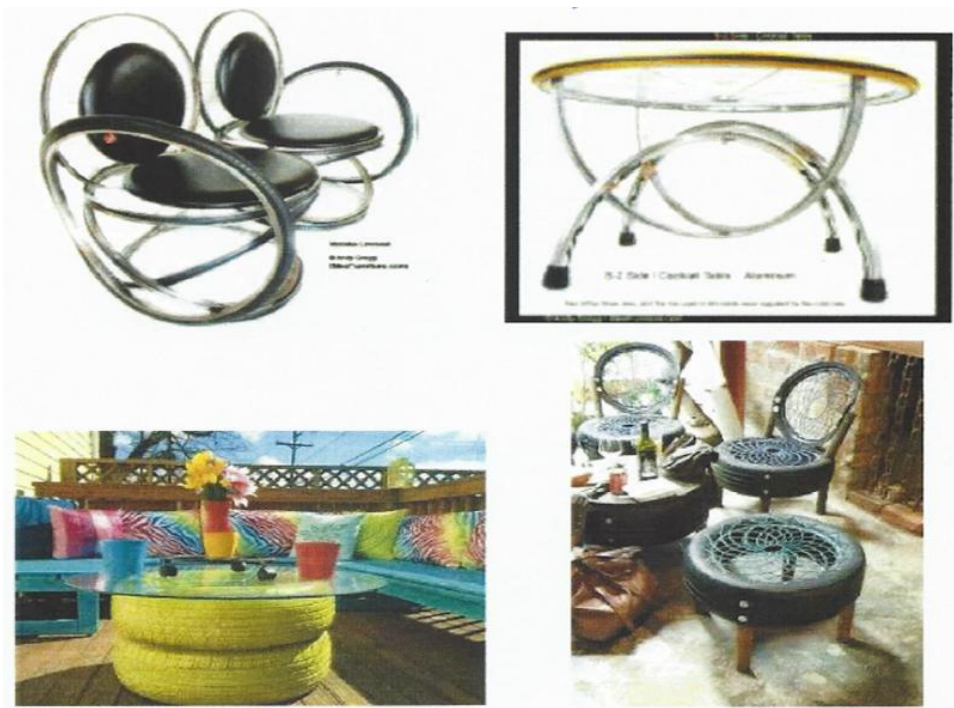
International Advanced Research Journal in Science, Engineering and Technology

Vol. 6, Issue 5, May 2019
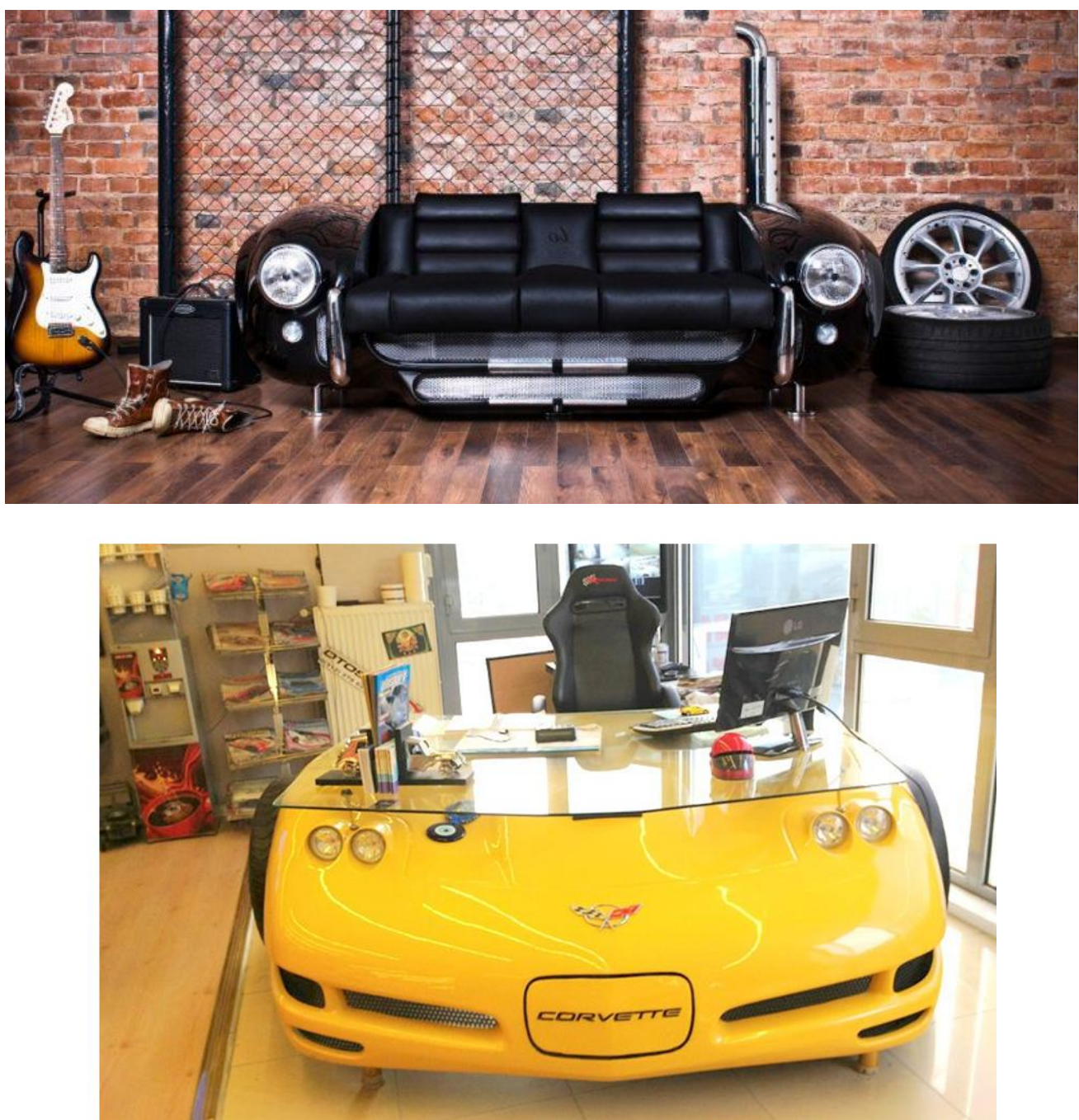

Furniture made from plastic boxes such as soda water boxes and fruit boxes (Fig. 7)

3. Furniture made from boxes such as soda water boxes and fruit boxes (Fig 6)
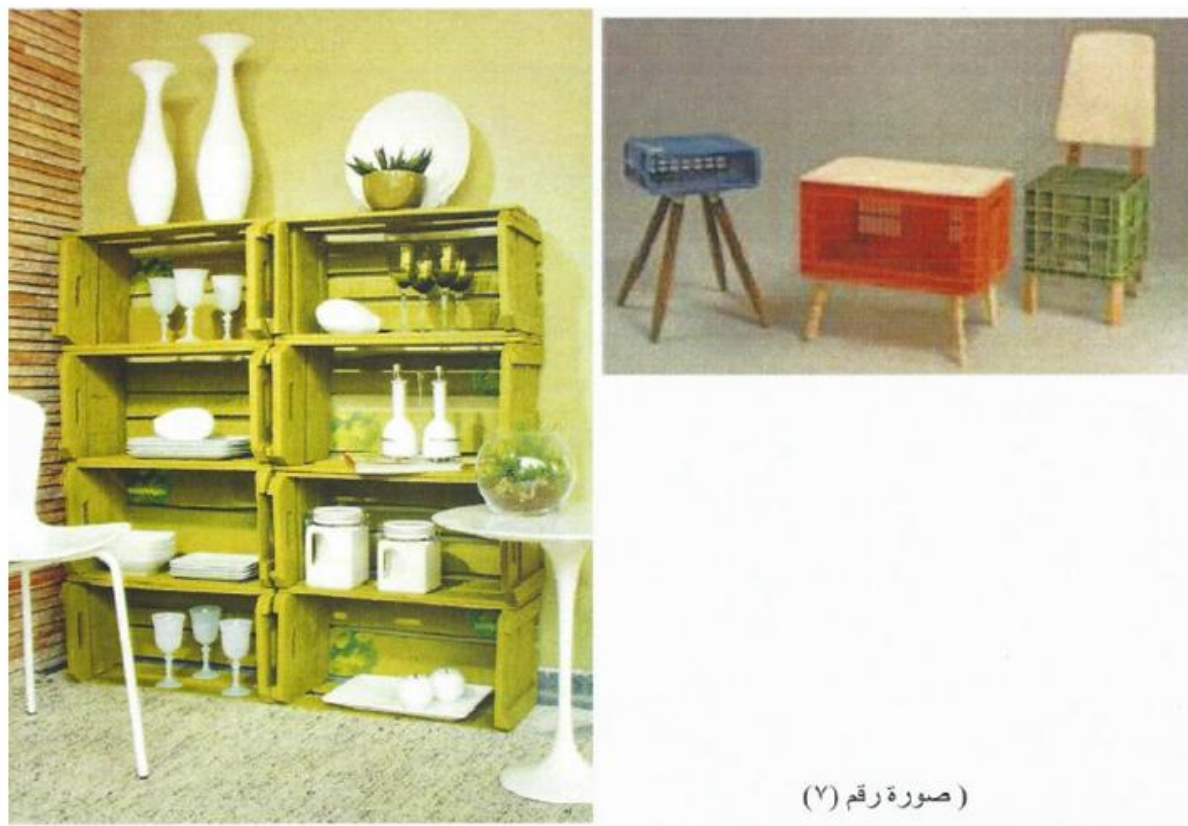

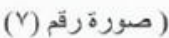




\section{International Advanced Research Journal in Science, Engineering and Technology}

Vol. 6, Issue 5, May 2019

5. Centre table made from old tree trunk. (Fig 8)

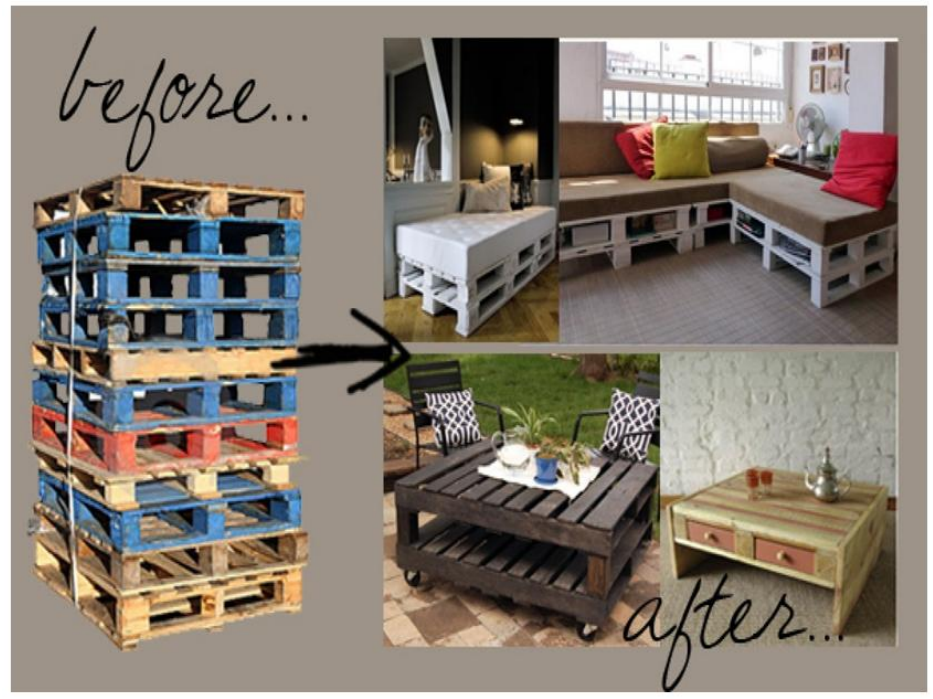

4. Chair made from old bag and add wooden leg (Fig 7)

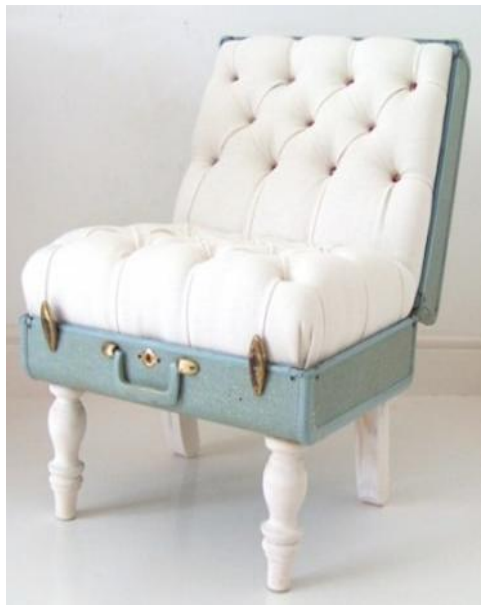

4. The use of old volume books as book preservation units (Fig. 8)
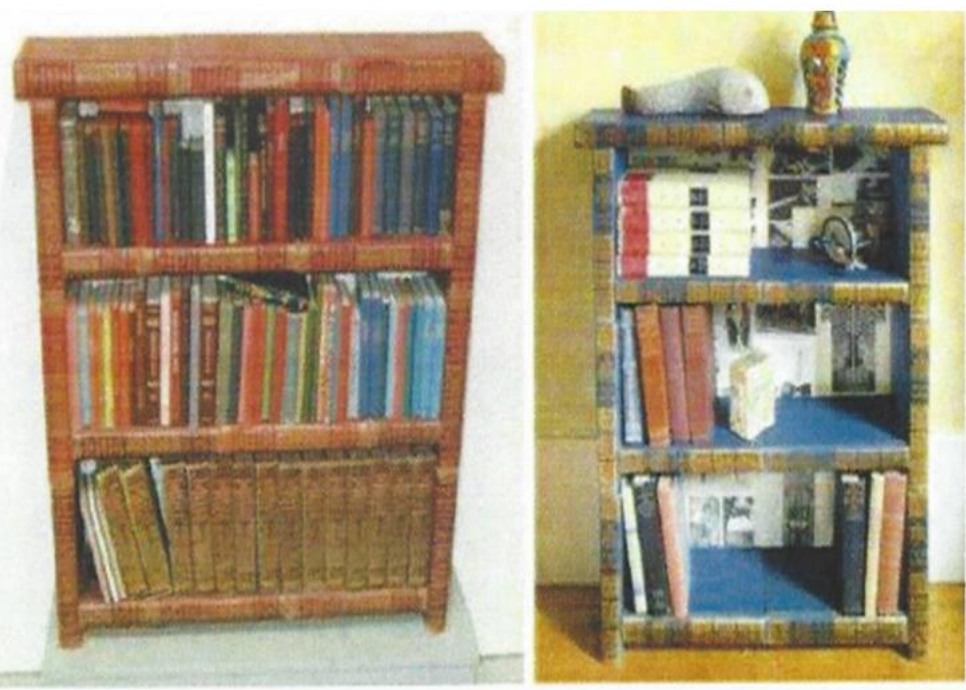


\section{International Advanced Research Journal in Science, Engineering and Technology}

Vol. 6, Issue 5, May 2019

5. Using old storage units (shelves) as a disk for new tables (Fig. 9)

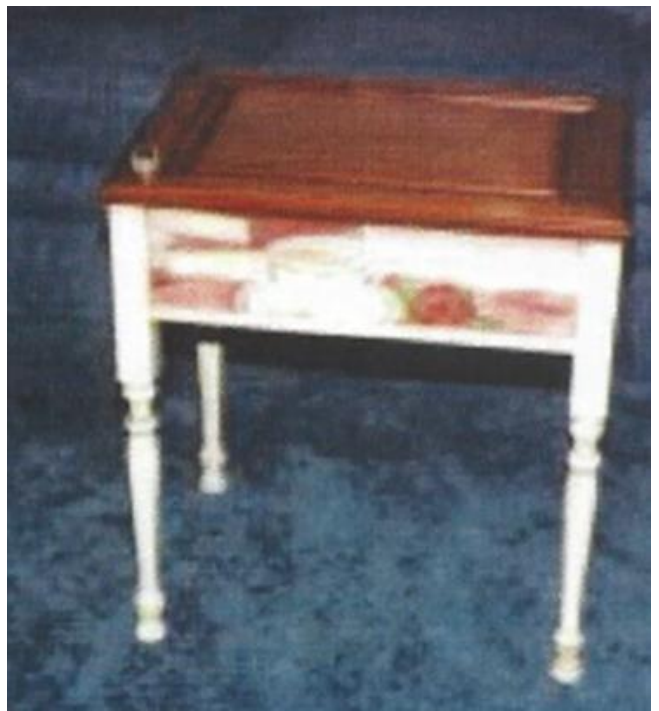

6. Using tree branches to make centre tables (Fig. 10)


There are many other ideas that achieve the concept of sustainable interior design. No doubt that there are great economic benefits from the spread of this thought because it achieves several gains, including the need not to recycle the same material and then re-manufacture, but using it directly in its original status. Trucing the cost of recycling and producing a low-cost product

\section{CONCLUSIONS}

At the end of this research, the following findings were found:

1- The application of sustainable design concepts is the best solution to overcome the problem of depletion of natural resources and non-renewable materials in the field of architecture and interior design.

2- Sustainable design is economically expensive compared to traditional design, due to the high cost of the equipment required to be incorporated into the building.

3- The increase in the cost of a sustainable building corresponding to the saving in the operating expenses of the building in the long-term.

4- Taking into consideration the application of sustainable design concepts before designing the building reduces the actual cost of the execution.

5- In most cases, the concepts of architecture and sustainable interior design are widespread in large buildings with large budgets, while not widely used in small or residential buildings.

6- Despite the economic and environmental efficiency of recycled furniture, its use is not widespread in our Arab World because of our cultural heritage. 


\section{International Advanced Research Journal in Science, Engineering and Technology}

Vol. 6, Issue 5, May 2019

\section{REFERENCES}

[1]. The 5th National Forum on Environmental Economics and Its Impact on Sustainable Development - Faculty of Economic Sciences and Management Sciences, Ministry of Higher Education and Scientific Research - People's Democratic Republic of Algeria 21 -22 October 2008

[2]. Mahmoud Ahmed Essa - Professor of renewable energies and sustainable urban design. The Faculty of Environmental Design - King Abdulaziz University - Jeddah - Saudi Arabia. Pdf

[3]. Architectureweek-Artifice-INC-2August- 2000

[4]. ASHRAE Fundamentals - 1997.

[5]. Fred A.Bernstein - www. interiordesign.net-6/1/2003

[6]. Nichoigas Tamarin-www. interior design.net-2/5/2009 .

[7]. Penny Bonda - www.interiordesign.net

[8]. http://en.wikipedia.org/wiki/Sustainability

[9]. http://en.wikipedia.org/wiki/Environmental_economics

[10]. http://en.wikipedia.org/wiki/Ecological_economics.

[11]. http:/Awww.arch.hku.hk/research/BEER/sustain.htm\#2.1

[12]. http://Awww.sustreport.org/issues/sust_comm.html 